\title{
A SUPERAÇÃO DA CISÃO INDIVÍDUO/GÊNERO - NECESSIDADES, INTERESSES E VALORES SÓCIO, HUMANO-GENÉRICOS ${ }^{1}$
}

lael de Souza 2

\begin{abstract}
Resumo
O esclarecimento das relações entre indivíduo e gênero humano torna-se essencial no mundo hodierno para enfrentar o individualismo e hedonismo que aprofundam o aviltamento e esvaziamento dos seres humanos. A ética como condição mediadora para a superação da reificação e estranhamento dos indivíduos. Essas são algumas das questões analisadas e refletidas nesse artigo, visando potencializar a tomada de consciência de nossa verdadeira condição e das possibilidades de superá-la.

Palavras chaves: indivíduo; gênero humano; ética; sociabilidade capitalista.

\section{SUPERACIÓN DE LA CISURA INDIVÍDUO/GÉNERO - NECESIDADES, INTERESES Y VALORES SOCIO, HUMANO-GENÉRICOS}

\section{Resumen}

La clarificación de las relaciones entre el individuo y la humanidad se convierte en esencial en el mundo de hoy para enfrentar el individualismo y el hedonismo que profundizan la degradación y vacía de seres humanos. Ética como una condición para superar la cosificación del mediador y extrañeza de las personas. Estas son algunas de las cuestiones analizadas y reflejadas en dicho artículo, con el fin de mejorar la conciencia de nuestra verdadera situación y las posibilidades de superación.

Palabras clave: individuo; humanidad; Ética; sociabilidad capitalista.

\section{OVERCOMING THE SPLIT INDIVIDUAL / GENDER - NEEDS, INTERESTS AND SOCIAL VALUES,} HUMAN-GENERIC

\begin{abstract}
The clarification of the relationship between the individual and mankind becomes essential in today's world to face the individualism and hedonism that deepen the debasement and emptying of human beings. Ethics as a mediator condition for overcoming reification and alienation of individuals. These are some of the issues discussed and reflected in this article, aiming to enhance the awareness of our true condition and the possibilities to overcome it.

Keywords: individual; mankind; ethics; capitalist sociability.
\end{abstract}

\footnotetext{
${ }^{1}$ Artigo recebido em 22/09/18. Primeira avaliação em 01/02/19. Segunda Avaliação em 05/02/19. Aprovado em 11/04/19. Publicado em 04/07/2019. DOI: https://doi.org/10.22409/tn.17i33.p29378.

${ }^{2}$ Doutoranda em Educação pela UNICAMP - SP. Mestre em Ciências Sociais pela UNESP - Marília.

Professora Assistente da Universidade Federal do Piauí, curso de Licenciatura em Educação do Campo (LEDOC), campus Ministro Petrônio Portela. Membro do Núcleo de Estudos e Pesquisa em Emancipação Humana (NESPAM), UFPI - PI. E-mail: iaeldeo@gmail.com, https://orcid.org/0000-00025860-3352.
} 


\section{Introdução}

No mundo hodierno, regido pela lógica da sociabilidade capitalista onde prevalece o ethos operandi do individualismo, da competição, da concorrência e do egoísmo como imanentes à condição humana, indivíduo e gênero humano encontramse cindidos, pois o "cidadão" corresponde à igualdade jurídica, à emancipação política, que cinde o homem em duas dimensões: uma pública e outra privada, impossibilitando-o de se realizar enquanto um homem integral. Desde já, encontra-se fragmentado, preso à imediaticidade e as suas necessidades prático-utilitárias, voltado a si e para si mesmo, como uma monada, alimentando-se pela ilusória busca de uma felicidade individual.

Alienado de si, da consciência de como se faz ser social, fazendo-se a si mesmo, de sua consciência "em si", de que "é autor e produto de si mesmo, o que indica a historicidade ${ }^{3}$ de sua existência" (BARROCO, 2010, p. 20), portanto, não é capaz de se autodeterminar e realizar escolhas conscientes acerca das necessidades, interesses e valores que devem guiar suas ações e relações no mundo e com os outros.

Apropriar-se desse conhecimento e saber torna-se, na atual conjuntura e período histórico-social, uma tarefa essencial para uma nova atitude (visão de mundo) e comportamento (modo de proceder e agir) que pode contribuir para a retomada do seu lugar como sujeito da história, potencializando o reconhecimento e compreensão da indissociabilidade reflexiva entre indivíduo/sociedade, singularidade/universalidade, resguardadas suas especificidades.

Demonstrar como o homem se faz homem e se constrói como ser social e, assim, a própria história; as razões da cisão entre vida pública e privada, entre indivíduo e sociedade, entre indivíduo e gênero humano e de que maneira a ética pode contribuir para a transcendência positiva de todas essas formas de cisão será nosso objetivo com esse artigo a fim de que possamos nos munir para enfrentar e denunciar as formas de alienação moral que inviabilizam e obstaculizam a compreensão da unitariedade do ser social e a necessidade de priorizar determinados valores humano-genéricos para parametrar as escolhas entre as alternativas

\footnotetext{
${ }^{3}$ Historicidade que resulta do processo de acumulação das ações individuais que conformam a totalidade das relações sociais e de produção que produzem as sociabilidades humanas no tempo e espaço histórico-social.
} 
virtualmente postas - virtualidade que evidencia que as escolhas não estão ao alcance de todos, pois a verdadeira liberdade consiste na existência de alternativas e na possibilidade concreta de escolha entre elas, como ressalta Marx -, guiando os homens em suas ações e relações sociais e de produção.

\section{Da constituição do ser social - um ser natural humano}

Discorreremos sobre o surgimento do ser social a partir da fundamentação teórico-histórica-filosófica de Lukács (2013), embasado nas descobertas de Marx. Conforme o segundo, são as condições materiais que proporcionam a produção, desenvolvimento e reprodução da existência. O mesmo se aplica ao ser social. Sua existência pressupõe outros dois momentos distintos, porém, articulados entre si. Trata-se da esfera orgânica-biológica (o repor o mesmo) e da esfera inorgânica (o tornar-se outro). O primeiro garante as condições para a produção/reprodução da vida, como exemplo o corpo biofísico humano, cujo metabolismo, além de suas propriedades e legalidades imanentes, necessita do segundo momento, que é a natureza externa, inorgânica, onde ocorre o processo de mudança, realizando as transformações dos objetos naturais pela ação/interação com os demais elementos que compõem o mundo físico-natural. De modo que uma montanha, pela ação pluvial, eólica e também pela decomposição de restos vegetais, minerais e animais, além de diminuir de tamanho e alterar sua geografia - de montanha para planície -, forma, após milhares de anos, as bacias sedimentares. É o tornar-se outro.

Esses dois momentos, embora específicos, criam as condições para o salto ontológico que dá surgimento ao terceiro e à terceira esfera: do social, mais precisamente, do ser social. Após milhares de anos, um ramo da espécie dos símios, pelas experiências de ensaios e erros, de tentativas, resultando no construto de instrumentos e ferramentas - ainda que inicialmente rudimentares, imitação dos objetos naturais encontrados e colhidos na natureza, porém, sendo, ao longo do tempo, aperfeiçoados e melhorados, imitando aqueles que na práxis (nas tarefas cotidianas) demonstravam maior eficiência para o fim perseguido -, conseguem fixar essas experiências acumuladas, produzindo a assimilação, memorização e associação, o que permite o desenvolvimento de um sistema de reflexos condicionados, assim como nos animais. Podemos chamar a isso de "pensamento 
mecânico", de causa e efeito. Porém, a fixação dos meios exige, concomitantemente, para seu desenvolvimento, um processo de generalização ${ }^{4}$ e abstração, que criam as condições para a prévia-ideação, para a antecipação da objetivação da ação na mente do seu criador, originando o ato teleológico e causal do trabalho, protoforma do ser social.

Como afirma Lessa (1996, p. 35), "a busca e seleção dos meios impulsionam a consciência para além de si própria: impulsionam a consciência para o conhecimento do mundo exterior a ela". Ou então, como elucida Fischer (1973, p. 25), "os meios precederam o propósito; o propósito se revelou pelo uso dos meios". Ocorreu um salto qualitativo do pensamento mecânico para o pensamento consciente, operando uma transformação estrutural do ser que então se faz social. Os meios não são mais apenas procurados pela decorrência da assimilação, memorização e associação, para além, diferenciando-se dos demais animais, o ser que então se funda como humano, justamente por esse ato teleológico consciente, sabe o que precisa fazer, como fazer e para que fazer (propósito e finalidade da ação, teleologia). Avalia seu entorno, as condições e circunstâncias que compõem a situação com que se defronta e realiza escolhas entre as alternativas conhecidas, postas conforme as necessidades impostas, agindo de uma forma e não de outra, criando diferentes modos e possibilidades de fazer, diversificando suas ações e atividades.

A mediação para o salto ontológico e estrutural do ser é a consciência, intercedida pela ação mediativa fundante, que é o trabalho, a interação homem/natureza, por isso um metabolismo mediatizado, colocando como premissa uma verdade objetiva inconteste: o ser social é um ser natural-social, um ser humano natural. Isto nos coloca uma questão extremamente vital e relevante: desde sua origem e fundação como homem, o ser social afirma e reafirma sua base natural como condição de sua humanização, ou seja, o desenvolvimento da "consciência de si" exige e impõe o reconhecimento da conexão ineliminável e inquebrantável, da interdependência e determinação reflexiva com as esferas orgânica e inorgânica, evidenciando que sua manutenção e reprodução deve ser compreendida enquanto

\footnotetext{
${ }^{4} \mathrm{~A}$ tendência à generalização é inerente ao trabalho, por isso ele é a categoria fundante do ser social. Conforme Lukács (apud LESSA, 1996, p. 37), a generalização ocorre "à medida que a experiência de um trabalho concreto é utilizado em outro trabalho, se produz gradualmente uma sua - relativa autonomização, o que quer dizer que são generalizadas e fixadas determinadas observações que não mais referem de modo exclusivo e direto a um único procedimento, mas adquirem, ao invés, um certo caráter de generalidade como observações que dizem respeito a eventos de natureza em geral".
} 
produto de mediações entre distintos complexos, constituindo-o enquanto uma totalidade, uma unidade, sendo, em si mesmo, a síntese de múltiplas determinações. Prova disso é o seu próprio corpo biofísico, um organismo natural, que necessita do inorgânico para se manter e reproduzir.

Isto evidencia, de maneira radical, que sua constituição como indivíduo, como veremos no momento oportuno, e o desenvolvimento de sua individualidade depende, reflexivamente, das relações mantidas e estabelecidas com a totalidade social e com a sociabilidade formada como produto da rica diferenciação entre os indivíduos proporcionada pelo acúmulo do saber-fazer e conhecimentos sistematizados pelas várias gerações humanas, produzindo a consciência "para si" através da constituição e consubstancialização do patrimônio histórico-cultural acumulado por toda a humanidade até o presente.

Por isso mesmo jamais o ser humano pode se esquecer de sua base natural, o que objetivamente demonstra que não se basta a si mesmo, que depende de outro(s) ser(es) - orgânico, inorgânico e demais seres sociais. Como assevera Mészáros (1981):
o verdadeiro eu do ser humano é, necessariamente, um eu social, cuja 'natureza está fora de si mesmo', isto é, define-se em termos de relações interpessoais, sociais, imensamente complexas e específicas. Mesmo as potencialidades do indivíduo só podem ser definidas em termos de relações de que ele é apenas uma parte. Para que alguém seja 'potencialmente um grande pianista', é preciso não só a existência de um instrumento social - socialmente produzido - como também a atividade, altamente complexa, do gozo musical seletivo. (Logo), a natureza humana não é algo fixado pela natureza, mas, pelo contrário, uma 'natureza' que é feita pelo homem em seus atos de 'autotranscendência' como ser natural. Não é necessário dizer que os seres humanos - devido à sua constituição biológica natural - têm apetites e várias propensões naturais. Mas no 'ato consciente, autotranscendente, de tornar-se' eles se transformam em apetites e propensões humanos, modificando fundamentalmente o seu caráter, passando a ser algo inerentemente histórico (p. 152-153).

É assim que compreendemos que o ser social ao transformar a natureza pelo trabalho cria-se a si mesmo como um ser distinto dos demais seres naturais, se faz como homem, construindo uma segunda natureza pela transformação da primeira natureza, produzindo o mundo humano, a natureza artificial, isto é, modificada em forma e função, correspondendo às variadas e renovadas necessidades humanas. 
O homem é, deste modo, demiurgo de si, o que elimina a ideia de um Deus ou criador. Ao se criar vai deixando sua marca no mundo através de seus feitos, de suas invenções e inovações, enfim, dos meios cujo desenvolvimento "fixa socialmente a acumulação realizada" (LESSA, 1996, p. 35), produzindo, assim, a história e a historicidade humanas pelos registros de sua passagem espaço-temporal, possibilitando que as gerações de homens do tempo presente enfrentem de maneira mais eficaz os problemas com que lidam, e pelo conhecimento e compreensão do passado possam agir de forma mais consciente e consequente como modo de delinear um futuro mais promissor ao desenvolvimento da humanidade e de sua realização na plenitude das condições e circunstâncias histórico-sociais, humanogenéricas possíveis.

Vemos, então, que a consciência "joga um papel fundamental, possibilitando que os homens respondam de maneira sempre nova às novas situações postas pela vida" (LESSA, 1996, p. 16). Como parte do processo que compõe a prévia-ideação, "só enquanto abstratividade pode ela ser o momento em que os homens confrontam passado, presente e futuro e projetam, idealmente, os resultados de sua práxis" (LESSA, 1996, p. 25). Ela é meio e órgão da continuidade do ser social, que por seu intermédio pode "se reconhecer em sua própria história e se elevar do seu ser "em si" para o seu ser "para si", de sua consciência "em si", para sua consciência "para si". A produção e reprodução das relações genéricas têm por mediação ineliminável a consciência dos indivíduos, e essas relações determinam, reflexivamente, o desenvolvimento de consciências genéricas. "Tomamos cada vez mais consciência do que somos, das leis que regem o nosso desenvolvimento, reconhecemo-nos coletivamente na nossa própria história" (LESSA, 1996, p. 65). Podemos dizer, portanto, que "isso significa que o gênero humano, ao se desenvolver, desenvolve também a sua autoconsciência, o seu 'ser-para-si'. Sem a fixação pela consciência dos resultados alcançados a cada momento pelo desenvolvimento da humanidade, esse desenvolvimento sequer poderia ser imaginado" (LESSA, 1996, p. 65).

Cabe-nos agora demonstrar como se dá a constituição do indivíduo, procurando estabelecer as condições e circunstâncias sócio materiais que possibilitam o processo de diferenciação entre os seres sociais, e já adiantamos que somente é concretizável pela formação e desenvolvimento das sociabilidades 
humanas, demonstrando e evidenciando as complexas mediações existentes entre indivíduo e sociabilidade.

\section{A formação humana: surgimento e desenvolvimento da noção de indivíduo e da individualidade}

As primeiras formas de organização humana, superando os bandos e o nomadismo como princípio de produção/reprodução da vida (corpo biofísico), ocorreram, em geral, com o processo de sedentarização, originando as sociabilidades humanas, conceito que significa, segundo MÉSZÁROS (1981, p. 157), “a imediação sensível dos indivíduos", ou seja, a interdependência entre eles como condição para o desenvolvimento de cada um, perfazendo a segunda natureza humana, que é a natureza historicizada do homem, criada por ele em seu processo de desenvolvimento e sistematização do patrimônio histórico-cultural acumulado. Ou ainda, segundo o autor, "o que não é um produto direto da natureza, mas criado através de um intermediário social, é natural na medida em que é idêntico à 'segunda natureza' do homem, isto é, a sua natureza tal como foi criada pelo funcionamento da socialidade". É assim que "só podemos falar de 'natureza humana' num sentido: no sentido cujo centro de referência é a modificação histórica e sua base, a sociedade humana" (MÉSZÁROS, 1981, p. 153). Por sociedade devemos entender uma "abstração", um conceito que faz referência a cada uma das particularidades individuais, generalizando-as. De modo que a sociedade é resultado das ações individuais (MÉSZÁROS, 1981, p. 1570).

Retomando nosso percurso, as primeiras sociabilidades humanas têm um modo de vida simples, pois as atividades produtivas desenvolvidas são também incipientes e rudimentares, já que dependem do processo de acúmulo de desenvolvimento dos meios (processos, procedimentos, técnicas, invenções, inovações, aprimoramentos, aperfeiçoamentos que buscam maior eficiência dos instrumentos, ferramentas e objetos em geral). Os seres humanos pouco se diferenciam entre si, havendo, nesse primeiro momento, uma certa homogeneidade nos modos de ser, sentir, agir e pensar, já que as principais diferenças consideradas entre os seres sociais é sua constituição biofísica e as limitações que, nesse momento processual do desenvolvimento humano, impõem uma determinada divisão das tarefas entre os sexos. 
Todavia, essas limitações são históricas, o que significa que podem e serão superadas em grau e dimensão cada vez maior com o desenvolvimento das forças produtivas (técnicas, tecnologias e ciência), o que cria condições para que o ser social possa realizar-se de modo multidimensional e multifacetado no futuro (isso quando a pré-história da humanidade, o modo de produção capitalista, for superada e iniciar-se sua verdadeira história, a sociabilidade para além do capital, transcendendo-o positivamente, isto é, não negando nem negligenciando as conquistas que representou para o gênero humano em termos de forças produtivas criadas e geradas pelo desenvolvimento científico, técnico, tecnológico, mas incorporando-as por superação), o que nos permite compreender o significado da máxima protagoriana de que "o homem é o limite do próprio homem", ou seja, o limite do homem atual - espaço e temporalmente delimitado e datado - são os conhecimentos acumulados, sistematizados e transmitidos até o presente momento por todas as gerações de homens que o precederam.

De modo que, nesse estágio do desenvolvimento das sociabilidades humanas, é a coletividade quem funda e fundamenta a diretriz e dinâmica da vida social. O bem comum é o princípio e a finalidade das ações e das atividades produzidas. Contudo, a partir do momento que novas necessidades vão surgindo como decorrência da satisfação das que as antecederam, as atividades produtivas humanas vão se multiplicando e complexificando, tornando, em consonância, mais complexas e mediatizadas as relações entre os homens. A riqueza dessa sociabilidade, da sua totalidade, produz, germinal e concomitantemente, as condições para o nascimento do indivíduo e da individualidade, dado que possibilita um processo de rica diferenciação entre os homens, pois ao gerar novas atividades antes inexistentes, novas necessidades, permite a descoberta de novas habilidades e o desenvolvimento dessas capacidades e potencialidades promove novas relações sociais e de produção entre os homens, ao mesmo tempo aumentando a interdependência entre eles, embora cada vez mais menos imediata e mais mediata, menos direta e mais indireta, constituindo-os, cada vez mais, enquanto totalidade social que se faz totalidade pela totalidade de suas relações sociais e de produção. A reprodução da vida humana torna-se, como diz Lessa (1996, p. 70), "crescentemente social".

Assim, deixa de haver uma identificação direta com o coletivo. Desenvolve-se a noção de que cada um possui necessidades específicas, diferentes entre si, que 
são indivíduos que se descobrem e reconhecem como individualidades, e tal descoberta deve-se à sociabilidade, à vida social, possibilitando uma diversificação cada vez maior e mais enriquecedora dos meios, que se aperfeiçoam e melhoram processualmente. Dessa forma, "quanto mais desenvolvida for a sociabilidade, mais numerosas e intensas serão as mediações sociais que articulam a vida dos indivíduos com a trajetória humano-genérica" (LESSA, 1996, p. 71).

$E$ é nesse momento processual que surge a noção e reconhecimento do homem como membro do gênero humano, isto é, como parte de um todo que o transcende, que é "trans-histórico", como afirma Barroco (2010, p. 75). Explicando: trata-se das necessárias mediações e nexos causais entre passado, presente e futuro, de descobertas humanas e de formas de enfrentamento das situações concretas vividas que transcendem o seu próprio tempo e permanecem como referencial que pode ser resgatado a qualquer tempo, por qualquer geração humana, conforme se faça necessário, correspondendo, assim, a necessidades, interesses e valores sócio, humano-genéricos, conquistas do gênero humano, portanto. Porém, ao mesmo tempo que o transcende também o contextualiza pelas determinações e situações que compõem o momento de sua história e historicidade espaço-temporalmente delimitada, particularizando e dando especificidade ao presente em relação ao passado e ao futuro, bem como particulariza e torna específicos também as histórias passadas em contraposição ao presente e às tendências que daí advém e permitem a virtualidade do futuro, do real.

Não por outra razão para Lukács apud Lessa (1996),

a unidade original, nitidamente perceptível nas sociedades primitivas, não é rompida pelo desenvolvimento social. Pelo contrário, esta unidade se enriquece e se complexifica, se realiza através de mediações sociais cada vez mais numerosas, diversificadas, complexas. O desenvolvimento do ser social não dá origem a uma crescente fragmentação do gênero, mas sim a um gênero cada vez mais socialmente articulado e, por isso mesmo, portador de uma unidade social cada vez mais rica e articulada. Por esse processo, 0 ser social se expressa, enquanto gênero, de forma cada vez mais complexa, rica e mediada - humana, enfim (p.71).

Quanto mais as sociabilidades humanas se desenvolvem e transformam em totalidades sociais complexas maior a necessidade de estabelecer os nexos e fundamentos causais - considerando também os casuais (acaso, espontâneo) - que perpassam as relações sociais e de produção. No entanto, de modo algum, em 
nenhum momento pode ser colocada em dúvida a determinação reflexiva entre 0 social e a constituição e surgimento do indivíduo, que como se faz individualidade com, pelo e através do social é, em si, um indivíduo social e suas probabilidades de ação individual são delimitadas pelas condições e circunstâncias da sua historicidade presente, que podem ou não ser potencializadas conforme a potencialidade contida na trajetória percorrida e experiências acumuladas pela humanidade.

A partir desses fatos podemos dizer que "quanto mais desenvolvido o ser social, mais ele se unifica objetiva e subjetivamente enquanto gênero humano socialmente construído, enquanto generalidade humana" (LESSA, 1996, p. 80). Isto porque "o desenvolvimento de um gênero humano crescentemente unitário tem como mediação ineliminável o desenvolvimento dos momentos de diferenciação e aumento da autonomia relativa de suas partes constituintes" (LESSA, 1996, p. 80). Compreendese, assim, que "as relações sócio genéricas aumentam em número e intensidade com o surgimento de formações sociais cada vez mais avançadas" (LESSA, 1996, p. 64$65)$.

Nos dias de hoje, a integração em nível mundial da humanidade ocorre com tal intensidade e com tal frequência, que a existência concreta de cada indivíduo (em larga escala independente de ter ele ou não consciência) está indissociavelmente associada à trajetória de toda a humanidade. Nos dias de hoje, o que ocorre em cada parte do mundo diz respeito a todas as pessoas: nossas vidas individuais estão tão articuladas com a do gênero humano que a trajetória deste último determina, em larga escala, o destino de cada indivíduo (LESSA, 1996, p. 64-65).

É justamente esse processo de construção, do devir humano e de humanização dos homens através do acesso e usufruto às criações das várias gerações humanas que possibilita que cada um descubra e desenvolva suas habilidades, capacidades, como também confronte os valores, necessidades e interesses particulares com os valores, necessidades e interesses sócio, humano-genéricos, contribuindo para que os seres humanos se elevem do seu "em si" para o seu "para si" e se reconheçam como generalidade humana, como membros do gênero humano, como individualidades surgidas a partir da riqueza e complexidade geradas pelo desenvolvimento permanente das sociabilidades humanas em sua complexificação contínua devido às novas necessidades postas e exigidas pela articulação cada vez mais mediada e complexa entre os seres humanos. 


\section{Da cisão entre indivíduo/sociabilidade humana, entre indivíduo/gênero, entre público/privado}

Embora a noção de indivíduo e a individualidade sejam momentos processuais do desenvolvimento e complexificação da organização das relações sociais e de produção das sociabilidades humanas, demonstrando que são produtos sociais, ao mesmo tempo também produzem transformações na estrutura da vida e dinâmica sociais através de suas ações individuais, trazendo repercussões na vida dos demais indivíduos sociais justamente pelas mediações que interligam e articulam as relações sociais e de produção no mundo dos homens. Todavia, uma mudança radical ocorre com o surgimento das formações socioeconômicas capitalistas e seu modo de produção correspondente. É nesse momento da processualidade histórico-social humana que ocorre a cisão entre público/privado, entre indivíduo/gênero, entre indivíduo/sociabilidade humana. Tracemos brevemente as principais causas desse fato.

De modo geral, como demonstram Mészáros (1981) e Tonet (2012), dentre outros autores, a necessidade de afirmação da igualdade entre os homens torna-se uma condição sine qua non para o fortalecimento do terceiro estado - liderado pelos burgueses, que nesse momento ainda não haviam se constituído como classe política, ainda que tivessem e concentrassem o poder eminentemente econômico - contra os privilégios mantidos pelo primeiro e segundo estados (estamentos, correspondente ao clero e à nobreza) durante o modo de produção feudal. Afirmar a igualdade natural e universal entre os homens, científica e filosoficamente, coloca em xeque a sustentação das desigualdades e privilégios entre os indivíduos.

Num primeiro momento, essa filosofia se transmuta em "filosofia de vida", servindo como parâmetro para identidade, solidariedade, fraternidade entre os vários segmentos sociais que compunham o terceiro estado, cuja liderança estava nas mãos da burguesia. Porém, num segundo momento, marcado pela tomada do poder político-social pela burguesia, a igualdade perde seu caráter universal, comum a todos os homens, e é mantida apenas na esfera da igualdade jurídica, como bem defende a "filosofia de classe", portanto, a concepção político-ideológica da classe capitalistaburguesa, restringindo-se à esfera pública-estatal.

Ainda que público e estatal não sejam sinônimos - uma vez que o primeiro corresponde às necessidades, interesses e valores sócio, humano-genéricos e o 
segundo aos interesses, necessidades e valores de uma classe específica que se apropria privadamente da riqueza socialmente produzida e se arvora como representante da humanidade. Entretanto, na verdade, utiliza do que deveria ser público para defender, garantir, propagar e legitimar seus interesses, necessidades e valores particulares como se fossem sócio, humano-genéricos -, são transformados em similitude na e pela sociabilidade capitalista. O Estado, como bem elucida Sanfelice (2005, p. 89-95) embasado no pensamento de Marx e Engels, é um aparelho jurídico-político-administrativo que tem como fundamento e finalidade primordial assegurar e proteger, defendendo e legitimando, a propriedade privada dos meios de produção. Aqueles que ocupam seus órgãos e instituições por intermédio de determinados cargos, embora sejam "escolhidos" através de regime representativo e do voto são, em sua maioria, provenientes dos segmentos dos grupos e da classe capitalista, de maneira que defendem seus interesses, valores e necessidades dizendo defender os interesses, valores e necessidades da totalidade social. Aliás, como é sabido, esses grupos e essa classe detêm o controle sobre os meios de produção e influenciam na própria escolha entre alternativas dos indivíduos, pois fabricam e produzem a opinião pública através da mass media, além de também fabricarem, produzirem e programarem os comportamentos, os hábitos, os valores, as necessidades que influenciam o ethos social (modo de vida, as relações sociais e de produção).

Assiste-se, assim, a cisão do homem entre cidadão e burguês, entre público e privado, para sermos mais exatos. A igualdade se dá apenas mediante a mediação do direito, da lei, da formalidade jurídica, e não de modo real, pois ela não é comum entre todos os homens, até porque a realidade é a do trabalho assalariado que torna o homem e sua força de trabalho uma mercadoria como outra qualquer, já que se centra no valor de troca desse meio de produção. Por isso precisa garantir a legitimidade da apropriação dessa força de trabalho pelo capital e suas personas, os capitalistas. Daí a necessidade do contrato social, base para a constituição da sociabilidade capitalista, como tão bem retratado pelos filósofos contratualistas, dentre eles, John Locke, pai do liberalismo econômico.

Igualar os homens formalmente significa torna-los proprietários, livres e iguais entre si, pois só assim são dadas as condições essenciais para o estabelecimento de acordos entre as partes. Os ditames da lei contratual suspendem, e 
momentaneamente fazem desaparecer, as desigualdades sociais reais entre os indivíduos sociais na esfera da produção social, correspondente à vida privada de cada um, remetida ao lugar ocupado por cada indivíduo na estrutura produtiva da divisão técnico-social-hierárquica do trabalho. Algo que, pela ótica e justificativa liberal, depende do pacote e banco de competências e habilidades adquiridas por cada um individualmente, descartando e desterrando as condições essenciais para isso, que deveriam ser públicas, ou seja, dadas e postas igualmente para todos, mas que não são e não estão, já que a produção da riqueza é social mas sua apropriação é privada.

Assim que cada vez mais as condições reais das relações sociais e de produção pressionam os homens a se voltar e fechar nos seus interesses, necessidades e valores particulares em detrimentos dos interesses, valores e necessidades sócio, humano-genéricos, contribuindo para que se alienem de si mesmos, não tendo conhecimento do que são, do seu "em si", de que suas vidas estão articuladas - e mediativamente são dependentes - às esferas orgânica e inorgânica, como também à sociabilidade humana, já que se fazem como indivíduos e constroem sua individualidade por intermédio do acesso, usufruto e apropriação da riqueza socialmente produzida pelas várias gerações de homens que os antecederam e produziram o patrimônio histórico-cultural acumulado pela humanidade. Não se reconhecem como membros do gênero humano, não são capazes de compreender, devido às relações sociais e de produção alienadas que engendram o estranhamento em relação às funções da reprodução social de suas vidas, que

determinadas descobertas dos homens, por sua relevância para o enriquecimento da humanidade, não se perdem na história. São duradouras e trans-históricas, permanecendo como conquistas do gênero humano, sendo, por isso, valoradas positivamente como parte da riqueza humana historicamente produzida e podendo ser resgatadas pelos homens em momentos específicos como exigências éticas e políticas humano-genéricas (BARROCO, 2010, p. 75-76).

Num mundo onde os caminhos para a felicidade e a realização são entendidos como essencialmente individuais, privilegiando os desejos, as pulsões, as vontades egoísticas, individualistas e consumistas, já que perdeu-se o referencial e parâmetro do social, do coletivo e da vida boa e do bem comum como pressuposto para a humanização dos homens, cada vez mais,

no âmbito da vida cotidiana, a consciência do indivíduo singular exclusivamente para seu eu; não é dirigida para o nós, os outros, a 
sociedade. No entanto, o eu é sempre social e a interação entre o indivíduo e a sociedade se faz, portanto, de modo social, referindo-se a valores e modos de ser sociais, como vimos. No entanto, por estar voltada prioritariamente para o $e u$, a dinâmica da vida cotidiana não permite que o indivíduo se dirija a exigências humano-genéricas. Para fazê-lo, ele terá que 'sair' dessa dimensão (BARROCO, 2010, p. 67).

A valorização e defesa da liberdade individual também é consequência da sociabilidade contratual capitalista, e o mais interessante é que a única liberdade do indivíduo é, na verdade, escolher a quem vai vender sua força de trabalho, para quem vai se subsumir em troca do assalariamento para manter a subsistência, porque em relação aos demais aspectos de sua vida, vive na ilusão de ter liberdade de escolha e de decidir, mas sem consciência de que lhe são negadas todas as condições, essencialmente sociais, para a realização de sua autonomia e desenvolvimento enquanto indivíduo. Conforme aponta Mészáros (1981),

a relativa liberação do homem em relação a sua dependência direta da natureza é realizada por meio de uma ação social. No entanto, devido à reificação (coisificação) das relações sociais de produção, tal realização surge numa forma alienada: não como uma independência relativa da necessidade natural, mas como uma liberdade para as limitações das relações sociais, como um culto cada vez mais intenso da 'autonomia individual'. Esse tipo de alienação e reificação, produzindo uma aparência enganosa de independência para o indivíduo, uma aparência de auto-suficiência e autonomia, transforma o 'mundo individual' num valor absoluto, em abstração da relação desse mundo com a sociedade, com o 'mundo exterior'. (...) A relação egoística é a camisa-de-força imposta ao homem pela evolução capitalista, e os valores da 'autonomia individual' representam a sua glorificação ética. (...) Mesmo que leve em conta os elos dos homens entre eles, essa ética só pode fazê-lo na forma de um simples 'deve'. (...) Nessa ética, o conceito de 'natureza humana' serve para absolutizar, como inevitabilidade metafísica, uma ordem social que 'mantém o homem em sua brutal solidão', lançando os indivíduos uns contra os outros, subordinando-os aos seus 'apetites artificiais' e ao 'domínio das coisas mortas sobre o homem' (p.233).

O egoísmo, portanto, é fruto das relações sociais e de produção capitalistas, não é parte da natureza humana, até porque esta é construída historicamente, não é dada de maneira inata, sendo, ao contrário, um produto social, já que o modo de vida, os valores que são ou não valorados pelos homens em cada período e época históricas, são criados pelas várias gerações humanas. Por isso mesmo que alguns valores se perdem, outros aparecem e alguns outros podem ser resgatados devido sua relevância e condição pressuposta para a criação de uma vida boa em prol do bem comum e dos interesses, valores e necessidades da coletividade humana. 
Porém, como a lógica da sociabilidade capitalista é a do contrato social, da igualdade, liberdade e propriedade jurídico-formal entre os homens, mantendo intacta a desigualdade social real existente entre eles em suas vidas privadas, a liberdade e a autonomia individual adquirem, como diz Mészáros (1981) a "santidade de um dogma, as referências sociais e políticas tendem a desaparecer e as circunstâncias, condicionadas sócio historicamente, da vida atomizada e privatizada do indivíduo são caracterizadas, a-historicamente, como a 'condição humana' (p.230)”. Os indivíduos se sentem cada vez mais impotentes e incapazes de fazer algo para mudar a realidade, pois não conseguem enxergar, reconhecer e compreender como são responsáveis pelas condições e circunstâncias que condicionam e determinam, reflexivamente, a vida de toda a totalidade social.

Em sua obra, Mészáros (1981) cita trechos do poeta Eliot, onde a heroína, Célia, “é tomada pelo medo de uma 'consciência da solidão' e ainda mais pela tentação de buscar explicações fora de si mesma, o que significaria atribuir a responsabilidade ao mundo em que vive" (p. 230), ou seja, tomar consciência de si, das limitações impostas à ação individual, porque a realidade é a síntese das relações complexas e mediadas entre a totalidade dos indivíduos sociais e deles com a humanidade através do patrimônio histórico-cultural acumulado e objetivamente posto e manifesto pelo nível de desenvolvimento das forças produtivas e que, portanto, não cabe ao indivíduo isolado resolver os problemas, males e mazelas sociais, pois eles são produto do modo como está organizada a estrutura das relações sociais e de produção que refletem e afetam a vida de cada um em particular. Logo, somente a articulação, organização e mobilização dos indivíduos em coletividades sociais poderia criar as condições para alterar e responder aos desafios e problemas que enfrentam.

Quando a heroína do poema de Eliot busca explicações para o que sente e se passa, não nela mesma mas sim no modo como as relações sociais e de produção estão articuladas, nas mediações políticas, econômicas, culturais e sociais presentes em cada fenômeno e fato cotidiano, buscando desvelar suas múltiplas determinações, seus nexos causais, compreende que o devir humano é feito e produzido pela totalidade de suas relações. Deste modo, ela denuncia a alienação humana, os constructos ideológicos e políticos criados para ludibriar e manipular os indivíduos, impedindo-os de compreender e enxergar a verdade: que foram alienados de si mesmos, de suas capacidades e potencialidades enquanto humanidade e são 
cobrados individualmente a fazer e ser o que só é possível enquanto coletividade humana, de modo a sentirem-se cada vez mais impotentes e incompetentes, permitindo que outros ajam, façam, pensem e sejam por eles, levando-os cada vez mais a uma vida contemplativa e não mais ativa, anulando-se como sujeitos históricos e produtores de sua própria historicidade. Esse seria o remédio para reconciliarmonos com a nossa condição humana, ou seja, a alienação inerente à vida humana.

Essas considerações aparecem no diálogo entre dois personagens do poema de Eliot, citado por Mészáros (1981, p. 231), que vale a pena reproduzir.

Célia: O que aconteceu me tornou consciente de que sempre estive só. De que se está sempre só.

... não que eu queira estar só, mas todos estão sós - ou me parecem estar.

Fazem barulho, e acham que estão conversando;

Fazem caretas, e acham que estão se compreendendo mutuamente.

E eu tenho certeza de que não estão.

Dr. Reilly: Posso reconciliá-la com a condição humana, a condição a que alguns, que foram tão longe quanto você, conseguiram voltar. Eles podem lembrar-se da visão que tiveram, mas deixam de se lamentar, mantêm-se pela rotina comum, aprendem a evitar as esperanças excessivas, tornam-se tolerantes consigo mesmos e com os outros, dando e recebendo, nas ações habituais, o que existe para dar e aceitar. Não se impacientam; estão contentes com a manhã que separa e com a noite que une, dispostos a conversa casual ante a lareira; duas pessoas que sabem que não se compreendem, criando filhos que não compreendem, e que nunca os compreenderão.

Célia: É isso o melhor da vida?

Dr. Reilly: É uma vida boa.

A solidão, o "estar só no meio da multidão", como também nos diz o poeta Drummond, é a tomada de consciência da alienação humana, de que os indivíduos sociais estão vivendo como se só houvesse presente, sem passado e perspectiva de futuro, sem nenhuma ciência ou compreensão de que são parte e membros do gênero humano e que o devir humano, concretizado na generalidade humana, é apenas uma frase oca, sem significado efetivo no cotidiano de suas vidas, cada vez mais fragmentada, regulada por hábitos que parecem ter existência própria e por normas, regras que já encontram prontas ao nascer e que têm que aprender para poder sobreviver no mundo, aprendendo a jogar o jogo da artificialidade da vida, também cada vez mais vazia, opaca, sem graça e sem sentido aparente. Como afirma 
Mészáros (1981, p. 231), "em condições semelhantes, a alienação pode assumir a aparência de um remédio. 'A condição humana' parece ser conviver com a alienação inseparável da existência humana, reconciliar-se com ela".

$\mathrm{Na}$ verdade, desaprendemos a con-viver, e só nos relacionamos quando colidimos com o outro, como é muito bem retratado pelo longa metragem Crash - No Limite. Todo nosso tempo é tempo produtivo ou de consumo, não há tempo para descobrirmos nossas habilidades, capacidades e nos realizar através dessas atividades, muito menos para estabelecermos relações verdadeiras, transparentes e sinceras, de verdadeira reciprocidade com os outros. O que realizamos através das relações que estabelecemos é a valorização das coisas e sua realização pela produção e consumo, repondo o ciclo, tornando-nos suportes materiais para realização dos produtos que fabricamos, de modo que nós nos tornamos coisas e os produtos os sujeitos a quem nos sujeitamos. Como diz a canção de Paulinho da Viola:

(...) Me perdoe a pressa. É a alma dos nossos negócios.

Oh! Não tem de que. Eu também só ando a cem.

Quando é que você telefona? Precisamos nos ver por aí.

Pra semana, prometo, talvez nos vejamos. Quem sabe?

Quanto tempo ... pois é ... quanto tempo...

Tanta coisa que eu tinha a dizer, mas eu sumi na poeira das ruas.

Eu também tenho algo a dizer, mas me foge a lembrança.

Por favor, telefone, eu preciso beber alguma coisa, rapidamente.

Pra semana...

O sinal ...

Eu procuro você

Vai abrir... vai abrir...

Eu prometo, não esqueço, não esqueço...

Por favor, não esqueça, não esqueça... Adeus...

Estamos sempre apressados, estressados, correndo, indo em todas as direções sem chegar, realmente, a lugar algum. Cansados, nunca sobra tempo. Todo tempo é calculado. Não nos perguntamos o que realmente é importante, necessário e o que, de fato, interessa e em quais valores embasamos nossas vidas para justificálas e plenifica-las de sentido. Além disso e junto a isso, como nos lembra Mészáros (1981),

(...) buscar o remédio na 'autonomia' é estar no caminho errado. Nossos problemas não resultam de uma falta de 'autonomia', e sim, ao contrário, de uma estrutura social - um modo de produção - que impõe ao homem um culto dela, isolando-o dos outros homens. A pergunta vital, que deve ser formulada sobre a autonomia, é: o que se 
pode fazer com ela? Se apenas a 'temos', como uma 'faculdade psicológica', um aspecto da 'estrutura do caráter', como um direito oco limitado à esfera da 'privacidade', para todas as razões práticas isso equivale à mesma coisa que não tê-la.

Ser capaz de fazer alguma coisa por meio da 'autonomia' envolve necessariamente 'o outro'. Em consequência, a única forma de 'autonomia' que vale a pena examinar é a 'autonomia não-autônoma'. Em outras palavras: a 'autonomia' humanamente significativa não é, na realidade, diferente da reciprocidade social, no curso da qual as pessoas envolvidas umas com as outras se adaptam mutuamente às condições de intercâmbio e, ao mesmo tempo, conservam o poder de iniciativa. Se a reciprocidade existe ou não, depende do caráter da estrutura social.

É evidente que o culto do indivíduo (...) só pode ampliar o abismo que separa o homem, no capitalismo, de sua integração social (p. 240).

O problema é que a reciprocidade inexiste na sociabilidade capitalista, pois estamos alienados de nossos verdadeiros interesses, necessidades e valores sócio, humano-genéricos que necessitamos resgatar e tomar como referenciais e parâmetros para orientar nossas ações, refundando e reestruturando nosso ethos de vida, superando o ethos e a moral tornados hegemônicos, que são os da classe capitalista e do capital.

\section{À guisa de conclusão: a superação da cisão indivíduo/gênero, indivíduo/sociabilidade humana}

Como aponta Lukács e é reafirmado por Lessa (1996, p. 96) "a contraditoriedade entre o genérico e o particular é um elemento fundamental na elevação à consciência, em escala social, do ser genérico dos homens". Por isso mesmo a moral, enquanto "um órgão de desenvolvimento da humanidade como um todo", no dizer de Mészáros (1981, p. 250), pode contribuir para essa elevação caso os indivíduos compreendam que se trata de um imperativo categórico que dizendo o que "deve ser" pode auxiliá-los justamente a reconhecer suas limitações enquanto indivíduo para realizar determinadas tarefas e reconhecer o peso e importância da humanidade presente na coletividade para potencializar ações mais efetivas.

Embora a moral seja um órgão de desenvolvimento da humanidade como um todo, é claro que ela só pode funcionar através das ações, mais ou menos conscientes, dos indivíduos. É inevitável, portanto, que na consciência dos indivíduos as diferenças (entre indivíduo e humanidade) sejam diluídas, ou totalmente eliminadas. O indivíduo 'assume' o peso total de representar a capacidade da humanidade em determinada situação moral, seja ele individualmente capaz, ou não, 
de corresponder às expectativas morais. Se assim não fosse, isto é, se a diferença objetiva entre sua capacidade muito limitada e os poderes praticamente ilimitados da humanidade não estivessem apagados na sua consciência através da linguagem categórica do discurso moral, o dever não poderia cumprir sua função: a consciência das limitações objetivas - que não pode ser divorciada de nossa avaliação, por mais inexata que seja, dessas mesmas limitações tenderia a fortalecer as pretensões do 'não pode ser feito', e enfraqueceria as do 'deve ser feito'. Em consequência, a moral tradicional só pode operar se o deve se impuser e apagar na autoconsciência do indivíduo todas essas diferenças objetivas que poderiam enfraquecer as pretensões categóricas dela. (...) Só o indivíduo abstrato da filosofia especulativa vive no reino das 'possibilidades' - o indivíduo real tem de satisfazer-se com o campo das 'probabilidades', dentro do qual precisa se mover, conscientemente ou não, satisfeito ou não. A oposição entre as categorias de dever e ser só pode ser resolvida se a elevarmos ao nível da humanidade. O que aparece como 'Dever', dirigido ao indivíduo nos termos específicos do discurso moral, expressa, na verdade, 'projetos' objetivos e as tarefas históricas reais que existem nas estruturas complexas da sociedade humana como necessidades e tendências de desenvolvimento (MÉSZÁROS, 1981, p. 250-252).

A moral, em termos de senso e consciência moral, faz com que os indivíduos reflitam em relação às ações e situações que enfrentam, obrigando os homens a pensar além de si mesmos, dos seus interesses, necessidades e valores particulares, eminentemente voltados às satisfações da própria singularidade, pois coloca em questão as normas e regras socialmente aceitas e legitimadas. Por isso mesmo muitas vezes, aparentemente, fica-se preso num impasse, sem resolução, porque, efetivamente, a superação dos problemas só pode ocorrer através de ações de vários indivíduos e não de um único isolado, já que trata-se de questões e problemas oriundos da forma como as gerações humanas e a geração atual, em particular, articulam, estruturam e medeiam as diversas instâncias da vida social.

É necessário inquirir sobre quais interesses, valores e necessidades a totalidade social se funda e fundamenta, pois só assim compreenderemos o tipo de relações estabelecidas e reproduzidas entre e pelos homens e poderemos dizer se elas contribuem para a realização e humanização de todos os homens ou para sua desrealização e alienação. Esse é o motivo pelo qual Lukács (apud LESSA, 1996, p. 98) aponta "uma diferença fundamental entre a ética e os outros complexos" sociais, como a moral, por exemplo, ou o direito, a tradição, etc. Para ele, "enquanto a moral, os costumes, a tradição, etc. se caracterizam por atuar no interior da tensão gênero/particular", atuando no interior dessa contraditoriedade enquanto instâncias 
mediadoras, mas incapazes de "encaminhar os conflitos e as alternativas no sentido de sua superação", a ética, por outro lado, atua "no interior da contradição gênero/particular, tendo em vista a superação da relação dicotômica entre indivíduos e sociedade" (LUKÁCS apud LESSA, 1996, p. 98).

Apesar de a sociabilidade capitalista ter como fundamento, princípio e fim a propriedade privada, o trabalho assalariado e a desigualdade social, contraditoriamente o desenvolvimento das forças produtivas - que é imanente ao seu próprio desenvolvimento e reprodução - cria uma contradição incorrigível e insuperável ao capital e ao sistema capitalista, evidenciando e permitindo aos homens reconhecerem-se e identificarem-se enquanto gênero humano, pois "na sociedade burguesa, a práxis social ${ }^{5}$ requer e possibilita que se eleve à consciência, em escala social, o fato de os homens serem os construtores de sua história, ainda que em circunstâncias por eles não escolhidas" (LESSA, 1996, p. 98). Assim,

ao permitir ao gênero humano se reconhecer como demiurgo de sua própria história, ao possibilitar a consciência, sempre em escala social, de que indivíduos e sociedade são pólos de um mesmo ser e que, por isso, compartilham da mesma história, essa nova sociabilidade funda uma nova necessidade. Qual seja, a superação da dicotomia indivíduo/gênero, a superação da cisão, tipicamente burguesa, do ser humano em citoyen e bourgeois. Tal superação requer, por um lado, que a práxis construa complexos sociais mediadores que permitam a explicitação e o reconhecimento coletivo das necessidades postas pelo desenvolvimento humano-genérico. E, por outro lado, que, nos atos teleologicamente postos pelos indivíduos, predominem valores que encarnem as necessidades do desenvolvimento da generalidade humana. A superação da dicotomia bourgeois/citoyen apenas pode se dar, primeiro, pela compreensão por parte do gênero do seu em-si, do que de fato ele é, o que implica necessariamente, também, a compreensão pelas individualidades do que de fato elas são, do seu ineliminável caráter genérico-social. Em segundo lugar, pela objetivação de valores predominantemente genéricos. Ou seja, a superação desta dicotomia apenas é possível com a elevação do gênero e da individualidade ao seu para-si. (E é) função específica da ética conectar as necessidades postas pela generalidade humana em desenvolvimento, com a superação do antagonismo gênero/particular (LESSA, 1996, p. 98-99).

Vemos, portanto, que por atuar no interior da contradição indivíduo/sociedade, gênero/particular, a ética é o complexo social construído pela práxis para auxiliar os

\footnotetext{
${ }^{5}$ Atividade finalística consciente, consequente, transformadora, que realiza uma necessidade humana e produz coisas que vão além da vontade imediata que as criou, pondo-se para os outros e contribuindo e auxiliando-os para que descubram, através de um outro, do que também são capazes, realizando-se como seres humanos.
} 
homens na tarefa histórico-social de superar a dicotomia indivíduo/generalidade humana, público/privado.

A questão é que numa sociedade de classes, como a sociabilidade capitalista, a moral dominante é a da classe dominante, que também impõe o seu ethos como dominante, o que contribui negativamente para que os valores, necessidades e interesses sócio, humano-genéricos não tenham condições objetivas de se concretizar. Isso significa, como afirma BARROCO (2010, p. 71),

que a moral está vinculada - contraditoriamente - ao desenvolvimento humano-genérico e à sua alienação, pois as formas de reprodução de valores ético-morais são orientadas por valores e princípios sociais e humano-genéricos, isto é, universalmente legitimados, mas que podem não ter condições de se universalizar em determinadas condições sociais. Neste caso permanecem como universais abstratos.

Tal contradição em relação à moral se explica porque, positivamente, ela

se estrutura através de princípios e valores universais abstratos apropriados pelos indivíduos em cada formação social concreta e situação histórica determinada de forma a ser materializados, de modo particular, em suas ações práticas. São princípios e valores ontologicamente objetivos, pois referem-se a valores genéricos que são produtos históricos de conquistas teórico-práticas do ser social, ao longo de seu desenvolvimento. Portanto, sua objetividade decorre do fato de pertencerem à história dos homens (BARROCO, 2010, p. 69).

Contudo, por outro lado, sua negatividade está na moral alienada decorrente da formação socioeconômica capitalista, pois "na sociedade de classes já não é possível uma unidade em torno de valores e necessidades comuns a todos os membros da sociedade" (BARROCO, 2010, p. 61), isso porque, como vimos, essa forma de sociabilidade valoriza o individualismo, a privacidade, o egoísmo, a concorrência e a competitividade, naturalizando-os, tornando o culto ao indivíduo e à liberdade individual (autonomia) um dogma sagrado, como demonstrado através de Mészáros, isolando cada vez mais os indivíduos, fazendo com que se sintam impotentes e incapazes, alienando-os de si mesmos e dos outros. É assim que determinados valores éticos, sócio, humano-genéricos deixam "de estar no cume da hierarquia dos valores por certos períodos históricos" (BARROCO, 2010, p. 70).

$\mathrm{Na}$ sociabilidade capitalista são os interesses privados em comum que aproximam os homens, permitindo que se agreguem enquanto for conveniente para cada um, utilizando dos outros como meio em benefício próprio. Tal atitude não é 
recriminada, embora possa ser rejeitada por alguns. Afinal, a concepção do ethos de vida admite, e como diz a canção, "ainda mais quando a subida tem o céu como limite" (Clara Nunes).

Combater esse estado de alienação, de "consciência da solidão" exige uma luta interna, tendo como momento predominante a retomada consciente do conhecimento do nosso em-si, do que somos, pois "quanto mais o indivíduo é capaz de 'reproduzirse como indivíduo social', menos intenso é o conflito entre o indivíduo e a sociedade, entre o indivíduo e a humanidade" (MÉSZÁROS, 1981, p. 256). Porém, a condição para isso é que o indivíduo "participe de maneira cada vez mais ativa na determinação de todos os aspectos de sua própria vida, desde as preocupações mais imediatas até as mais amplas questões gerais de política, de organização socioeconômica e de cultura" (MÉSZÁROS, 1981, p. 256).

Dizer que o indivíduo se reproduz como indivíduo social "equivale a dizer que a relação entre o indivíduo e a sociedade, entre o indivíduo e a humanidade, continua sempre uma relação mediada". Portanto, "a questão prática em jogo é a da natureza específica dos instrumentos e processos efetivos de automediação humana" (Mészáros, 1981, p. 256), que na sociabilidade capitalista, devido à cisão do homem entre público e privado, impedindo-o de ser um ser natural-humano integral, caracteriza-se por relações alienadas, invertendo a relação entre meios e fins, que deveriam estar em adequação e reciprocidade, superando a lógica perversa onde os fins justificam os meios. Isto porque, "segundo Marx, as relações humanas nãoalienadas caracterizam-se pela automediação, e não por uma identidade direta e fictícia com um Sujeito Coletivo genérico, ou com a dissolução do indivíduo nele" (MÉSZÁROS, 1981, p. 256). Daí decorre que "o problema (...) é a elaboração concreta e prática de intermediários adequados, que permitam ao indivíduo social 'mediar-se a si mesmo', em lugar de ser mediado através de" (Mészáros, 1981, p. 256) relações coisificadas e instituições que legitimam e perpetuam a alienação, como o Estado de Direito.

São os próprios homens, em associação, que devem organizar, planejar, controlar, decidir e estruturar os meios e as atividades produtivas e a reprodução social, tendo, efetivamente, as condições para a realização das escolhas, que devem estar e ser pressupostas a todos igualmente para que haja liberdade, de modo que existam, de fato, alternativas e haja a possibilidade concreta de escolha entre elas. 
Destarte, a objetivação das alternativas para as escolhas só estará pressuposta quando a propriedade privada dos meios de produção for erradicada e superada, quando o trabalho assalariado também for superado e quando os homens retomarem o controle sobre suas próprias vidas destruindo o Estado.

À guisa de conclusão, portanto, podemos dizer que no momento atual da história humana, os indivíduos encontram-se apartados da própria consciência de si, do seu em-si, dificultando, e muito - pela intensificação do hedonismo, do individualismo, do narcisismo, das relações cada vez mais desumanizadas, calculistas e reificadas entre os homens, transformados em meios e coisas, produzindo a barbárie que assistimos ao ligar a TV -, que consigam transcender positiva e conscientemente para sua consciência para-si.

Porém, como faz questão de enfatizar Barroco (2010), embora alguns valores sócio, humano-genéricos tenham sido desvalorizados em determinadas épocas históricas, eles permanecem como referência e podem ser resgatados a qualquer momento por uma determinada geração de homens, restabelecendo, através da reflexão ética, os princípios e valores que primam pela vida boa e pelo bem comum como condição para a realização de cada um, segundo suas necessidades, conforme a plenitude possível pressuposta pelo patrimônio histórico-cultural acumulado pela humanidade até aquele preciso momento processual do seu desenvolvimento marcado por avanços e recuos, fazendo avançar ou recuar, concomitantemente, determinados valores que ora se concretizam, ora se tornam novamente abstratos, mas mesmo assim permanecem como conquistas do gênero humano, podendo servir para guiar uma determinada geração de homens para a transcendência positiva da sociabilidade capitalista e do capital.

\section{Referências}

BARROCO, Maria Lúcia S. Ética - fundamentos sócio históricos. $3^{\mathrm{a}}$ ed. São Paulo: Cortez, 2010. (Biblioteca básica de serviço social; v.4)

FISCHER, Ernest. A necessidade da arte. Rio de Janeiro: Zahar Editores, 1973.

LESSA, Sérgio. A Ontologia de Lukács. Maceió: EDUFAL, 1996. (Série Didática Edufal, 2) 
LUKÁCS, Gyorgy. Para uma ontologia do ser social 2. Trad. Nélio Schneider, Ivo Tonet, Ronaldo Vielmi Fortes. 1 ed. São Paulo: Boitempo, 2013.

MÉSZÁROS, István. MARX: A Teoria da Alienação. Rio de Janeiro: Zahar Editores, 1981.

SANFELICE, José Luis. Da escola estatal burguesa à escola democrática e popular: considerações historiográficas. In: LOMBARDI, José Claudinei; SAVIANI, Dermeval; NASCIMENTOS, Maria Isabel Moura (orgs). A Escola Pública no Brasil - História e Historiografia. Campinas, SP: Autores Associados: HISTEDBR, 2005. (Coleção Memória da Educação)

TONET, Ivo. Educação contra o capital. 2 ed. rev. ampl. São Paulo: Instituto Lukács, 2012. 